\title{
Innovative understanding of the role of gender relations in anthroposociogenesis modern science
}

\author{
Tatyana Eroshenko ${ }^{1, *}$ and Anastasia Melnik ${ }^{1}$ \\ ${ }^{1}$ Don State Technical University, Gagarin Square, 1, Rostov-on-Don, 344003, Russia
}

\begin{abstract}
This article clarifies the role of the relationship between the sexes in the process of anthroposociogenesis. The source material is objectively limited. We rely on the ethnographic and archaeological material, which is analyzed in the works of historians and philosophers who worked, as a rule, within the materialist concept of anthroposociogenesis, i.e. the genesis of consciousness and society based on labor activity [B. Porshnev, S. Tokarev, Yu. Semenov, L. Feinberg, etc.]. The concepts that take into account the role of the sexual aspect, i.e. the fact of sexual dimorphism [Yu. Novozhenov and Yu. Borodai] are analyzed as well as a significant number of works by foreign ethnographers and psychologists, in which we find numerous private regulations directly or indirectly related to this issue [Dg. Fraser, L. LeviBruhl, K. Levi-Strauss, etc.]. The synergetic model of anthroposociogenesis plays an important role [N. Moiseev, A. Nazaretian, S. Kurdyumov, E. Knyazeva, etc.].
\end{abstract}

\section{Introduction}

The relevance of the genesis of relations between the sexes is determined by the fact that the very ancient theme of the emergence of the human race and the problem of social gender are now converging, declaring themselves interested in gender studies around the world, which suggests a new paradigm of culture and a new view of the entire human history [1-6]. Our hypothesis says that the relationship between the sexes is one of the driving forces of self-building and self-reproduction of the anthropogenetic system during the transition from the purely biological evolution to social, i.e. moral. First of all, it is necessary to state the general assumptions that we accept as the initial ones that do not cause doubts.

\subsection{The world concepts of anthroposociogenesis}

According to the generally accepted concepts of the world prehumans did not pratically differ from animals. They were collected in herds within zoological and/or harem families, bachelor groups and a zoological hierarchy that determined the (status) of dominant and the

* Corresponding author: eroschenko-1970@mail.ru 
(status) of dominant individuals was preserved. The term "zoological" families is used in a broad sense - any zoological, relatively stable form of relationship between males and females, including the form of a harem, and in a narrow sense - the stable interaction of a pair: a male and a female. The primitive people may have had zoological families in a narrow or broad sense, both of which were natural zoological formations. In the prehuman herd there were constant skirmishes with zoological and harem families that clarified the system of dominance, fights over females similar to those that occur in the modern ape herd. But unlike the apes our ancestors used stone tools. As shown by archaeological excavations many skulls of archanthropus and paleoanthropus show lifetime holes-evidence of violent fights. Strong and healthy members of the team died, and most importantly, the production process was disrupted, which negatively affected the situation of the team as a whole and actually led to its self-destruction. On the contrary, those teams that had the least losses were in a winning position. This could be the case in which zoological dominance and harem families were dissolved, where the sexual needs of adult members of the collective were met without serious collisions and numerous deadly fights, which may have been the case when the males refused under the pressure of the herd as a whole from zoological dominance and went to "promiscuous" sexual relations, i.e. promiscuity, apparently simultaneously associated with the prohibition of sexual relations in certain conditions and at certain times. Promiscuity was the initial form of regulation of relations between the sexes for child production, rising above the biological content. There is no definite data on the type of sexual relations among ancient people, but in principle three possibilities were discovered: monogamy, polygamy and promiscuity.

\subsection{The start of human history}

The only point that needs to be reconsidered is the question of the origin of the state from which the movement to the genus began - the state of disordered communication of the sexes or promiscuity. At the base of the arguments that cast doubt on promiscuity is the conclusion that at one time, the classic anthropologist L. Morgan was mistaken in defining the type of family relations of the inhabitants of the Hawaiian Islands as punalua (the transition from a blood-related family to a generic society). As for their sexual relations, they were not primitive animals, but very multiform - from pair marriage to polyandry, polygamy and great sexual freedom, characteristic rather of civilized societies. This example of the hypothetical punalua family makes it even more difficult to question the veracity of statements that attribute promiscuous and promiscuous sexual relations to early associations of people. This circumstance confirms the description of gender relations of primitive peoples of the nambikwara tribe in the territory of America as a special type of polygamy. Instead of a plural marriage, they had a monogamous marriage, to which extramarital relations were added. The older wife played the role of spouse in a monogamous family and followed the division of labor between the sexes, and the secondary wives she called "daughters" or "nieces", the latter did not participate in domestic work and were idle. However, in this case we are talking about the wives of the leaders. Despite the expressed doubt about the existence of promiscuity, the concept of sexual contract, in our opinion, does not conflict with the position that recognizes promiscuity. The latter is not reduced to promiscuous sexual relations, but is the first and more progressive stage of human evolution that denies zoological forms of the family.

\section{The genesis of the relations between the sexes}

We do not know exactly how the displacement of zoological family forms occurred, but this form is traditionally referred to as "promiscuity". A herd with "promiscuity" is no 
longer a herd of animals. The promiscuous festivals pointed to confirm the existence in ancient times of forms of relations between the sexes that deny zoological families, but are neither polygamy nor monogamy in the modern sense [10]. Considering the genesis of the most important social features (labor, production, society), researchers focus on two types of labor that act simultaneously as characteristics of two stages in the development of mankind: the first - animal-like, instinctive primitive labor, corresponding, apparently, to the primitive herd; the second - social labor (neoanthropus labor) already existed in the tribal community as the first form of society. It is arguable that the instinctive primitive animal-like labor of man living in a primitive herd was practically the same as that of animals, even those of the lowest animals, such as bees. It seems that in the same degree that the primitive herd of man was a pre-social organization, the instinctive primitive labor of the anthropoid was the precursor of social labor.

In general, considering the process of sociogenesis the task was not previously set to identify the role of the evolution of the relationship between the sexes in this process. Neither the most ancient dual organization, nor the gentile system in general and its stages, nor exogamy or other aspects of family marriage relations - none of this has been the subject of the historical and philosophical-scientific research until now. However, despite the fact that the problem of relationships between the sexes in sociogenesis is not affected, the historical and anthropological information provided to us indirectly resonates with concepts that take into account the role of the sexual factor. The most important event that ultimately had a positive impact on the relationship between the sexes and contributed to the consolidation of the primitive collective and its development was the formation of a new attitude to the results of labor (hunting, gathering). This attitude was manifested in the treats and gifts of each other. Women mothers and their children benefited most from the gift system.

\subsection{The concept of the sexes genesis by Yu. Semenov}

The position of $\mathrm{Yu}$. Semenov, who considered the base of family and marriage relations at the very initial stage of society in his work «How mankind appeared» (2002), is noteworthy. The anthropological and ethnographic material on which it is based is quite rich and has not lost its value today, as evidenced by the reissue of the first book. In the history of the primitive human herd, two stages can be distinguished: the primitive human herd with an amorphous structure, without zoological harem families with unlimited promiscuity, but with a ban on restoring the structures of the zoological family (perhaps this herd was formed by Homo hobilis (a working man) and the primitive human herd with a limited promiscuity and with a sex-and-age structure (men, women and children - the herd Homo erectus (a walking erect man). The restriction of promiscuity acts as a continuation of the social regulation of sexual relations and is associated with the objective need to prohibit sexual relations during the preparation and conduct of vital events for the human team: the preparation and conduct of collective hunting, which was the main type of work in the prehuman herd that determined the conditions of human life. The success of the hunt largely depended on preliminary training. The production of primitive tools required a lot of time, and conflicts distracted people, reducing the chances of success of an event that was vital for all members of the team, and putting it at risk of starvation. It was possible to completely eliminate conflicts during the preparation for hunting by prohibiting sexual relations during this period. Intuitively feeling the importance of abstinence at such a crucial moment in the life of the herd, the team members began to monitor strictly the implementation of the sexual hunting and production taboo. Those who violated it were punished: probably expelled from the collective, condemning them to starvation. The duration of the taboo could be very different: ethnographic data show that some tribes have 
only one night before the hunt (swans, pygmies, huichols, motu of New Guinea), others up to several weeks or even months before the hunt (carrier, nootka, melanesians of the island of Ireland). With the expansion of human industrial activity the periods of abstinence in sexual relations became longer. Not only hunting, but also any labor activity required expanding the scope of sexual taboos. A necessary consequence of long periods of abstinence was violent sexual intercourse in those periods when people were free from economic activities. These periods turned into promiscuous holidays, which were accompanied by a kind of orgies, dancing, shouting and promiscuous copulation.

In most peoples' copulations during promiscuous holidays were attributed as the magical properties to promote the reproduction of animals and the development of plants. Our ancient ancestors personified the forces of the plant world in the form of male and female beings. Magic spells aimed at making forests and fields turn green and crops sprout were accompanied by sexual intercourse, which was an integral part of the rituals. Ancient people combined the process of procreation in humans with a similar process in plants and animals, and believed that communication between the sexes could speed up their appearance and growth. There are two opposite traditions. The first is based on the understanding that an ancient man takes part in the reproduction of plants and animals by his lust. The second is based on the idea that the unspent energy for reproduction of their own offspring goes to the reproduction of the plant and animal world. From the above, for further discussion, we note the following: the reason for the appearance of various types of sexual abstinence (taboo) is the conflict between the instinct of self-preservation and the instinct of reproduction. The first, based on providing oneself with food, subordinates the second.

Another very important factor that contributed to the physical improvement of mankind and positively regulated the birth rate of healthy offspring were age-related initiations. According to the concept of Yu. Semenov, the initiations were held by both boys and girls; they testified to their puberty, that they become full members of the collective and can participate in promiscuous holidays. The purpose of the initiations was to introduce the younger generation to the laws of the collective and the norms of behavior that should be followed. The initiations over young men were accompanied by quite severe tortures, which are a test of willpower. Such tests prepared young men for adult life, including sexual life, assuming mandatory adherence to taboos, i.e. the ability to abstain, switch sexual energy to useful activities for the team. L. Levi-Bruhl gives an example from the life of primitive people, that the old man Vainimala did not make any distinction between uninitiated men and children. In his story he connected all of them under the name of koiran: they are children. He also reports a lot of facts, which are typical to the different ancient cultures, describing the procedure of passing initiations simultaneously by both father and son or uncle. Therefore, there is a reason to say that the initiations are not a gender and age boundary, but rather a mystical (spiritual) one. During the initiation (especially for young men) the very severe tests were undoubtedly performed, but their main purpose was not to teach courage, endurance, courage, or the ability to keep secrets. Their main goal is to achieve some mystical result, which is based on the principle of patriciation. This principle is characteristic of logical thinking, it means not physical participation, but spiritual participation, which is captured by the meditative experience. A connection is established between the newly consecrated and the mystical reality of the totem collective. All their attention is focused on the moment that is the only one that matters: the state of special receptivity to which the initiates must be brought in order to achieve the desired patriciation. This means that all activities related to exhaustion and causing pain are aimed at leading a person to lose consciousness, a kind of trance caused by physical and nervous overstrain. The state of depersonalization of the subject means "death" and the next "new birth". The passage of initiation marks not just maturation and 
transition to an adult age group, but reincarnation, the introduction of a new soul, a new entity that participates in the totem, its rules and norms of behavior, especially sexual. The evolution of the primitive human herd in the direction of increasing social characteristics in it has led it to a contradictory, crisis state. On the one hand, the primitive human herd turned into a single, fairly strong collective, which realized its unity in the form of totemism. On the other hand, it became self-contained (turned into a closed collective from other human groups), which led to a crisis of child production and at the same time to a crisis of biological evolution (a crisis of sapientation). The way out of this state is due to the final withdrawal of sexual relations from the inner life of the herd and the establishment of sexual relations between members of the different collectives: the herd organization of human collectives has turned into a dual-herd, and the latter - into a dual-generic. Totemic (endogamous) collective, dual-herd and dual-generic organization-the stages in which the evolution of primitive social androgyny, the creative collaboration of two social groups: male and female, found expression. Sexual relationships between anthropoids played a crucial role in the transformation of the human herd into human society. Conflicts based on sexual competition and status sex had to be resolved, in his opinion, in two ways: by refusing sexual activity at all, or by distributing females through the establishment of a sexual contract. The second way has survived evolutionarily, i.e. females were distributed by a sexual contract, which is the basis of the concept of family unions and sexual division of labor.

It is safe to say that the sexual contract is the basis not only of ecological, but also of cultural adaptation. There is almost no difference in brain and hand development between males and females. Differences emerged with the birth of culture and the division of labor functions between the sexes. A significant role in sexual differentiation was played by two circumstances of the female: frequent pregnancy and the need to give birth to cubs with large brains and skulls, which made the female pelvis less adapted for running. She was not able to compete with men on the hunt. The latter circumstance made the woman dependent on the man, and she was faced with the task of keeping him. This fact is the central problem of the subsequent evolution of women, it is associated with the formation of its attractive morphological features. Since man, the only one of almost 20 primate species, was able to consciously bring prey to his fellows, with the advent of hunting for large animals and game, there was a division of labor and there were hunters whose duties were to feed those who could not hunt (i.e., they could not hunt) - cubs with a long biological childhood and a female burdened with children and pregnancy). A sexual contract was concluded between a female or group of females and a male, which performed three functions: food, sexual, and educational. In general, the sexual division of labor resulted from the fact that due to their biological nature women take care of genetic inheritance and men create a culture by their work.

\subsection{The concept of the sexes genesis by Yu. Borodai}

In his works «Erotica-death-taboo: the tragedy of human consciousness», (1996) and «Value and knowledge. The nature of moral and cult representations» (1996) Yu. Borodai considers the starting point of anthropogenesis as a biological impasse connected with the self - destruction of certain Primate species-communities of terrible predators, constantly erotically excited and armed with primitive tools, who have mastered the skill of killing their own kind. In such a community of constantly competing individuals, attempts to satisfy their sexual needs often ended in the death of the competing individuals because of the female. The motivating factor for further human evolution was the "gestalt representation: eroticism-death-taboo", because in the consciousness of the individual the sexual act and death merged together. We are talking about the ability to switch erotic 
energy into the energy of the human intellect, i.e. to carry out sublimation. The latter is the basis for overcoming the actual biological nature of man and passing into a superbiological being. It became necessary to suppress purely natural sexual instincts through taboos, and the capacity for fantasy allowed real sexual satisfaction to be replaced by ideal reproduction. "It is the most severe self-suppression of all manifestations of eroticism and aggression organically associated with erotic motives that caused the emergence of archaic forms of the human community proper - the first totemic forms of exogamy with their internal moral prohibitions (taboos) based on conscience." "Conscience" is primarily an emotional experience of fear that occurs in an individual when trying to break a taboo, even in the form of fantasy. Of course, if by conscience we mean something like the individual's own idea of the subsequent punishment for violations of the ban. We believe that the primitives of morality as a special form of social regulation did not yet exist, therefore, there was no conscience as an intrapersonal regulator.

\subsection{The concept of the sexes genesis by N. Moiseev}

Another variant of anthroposociogenesis is presented by N. Moiseyev in his work «The fate of civilization. Path of reason» (1998). Based on the synergetic model of bifurcation development, N. Moiseev presented anthroposociogenesis with three large points of "bifurcation". The first pulled man out of the animal world (turning to tool-making). The second is related to the emergence of morality. The third was marked by the creat ion of artificial biosystems. The concept of morality in N. Moiseev` work is used quite widely as a synonym for social culture, moral norms - as social norms, and he wrongly separates the first "bifurcation" from the second. Let's consider the second point of bifurcation, connected with the transition from purely biological evolution to social forms of consciousness. Due to the abstraction of his concept, it does not reflect the evolution of the relationship between the sexes, but in some points it resonates with our research. In particular, he notes the fact that within the primitive collective the relations are formed, which are different from the animals ones in the herd, in the flock. These relationships created the conditions for the preservation of craftsmen and other information carriers. $\mathrm{He}$ notes that these individuals in the chivalrous fights for the female could hardly stand up against stalwart fellows with heavy fists and not very developed intelligence. Such conditions were created by the rejection of zoological families and the establishment of promiscuity. Apparently, the smaller focus of aggression within the team built the advantage of cromagnons in front of neanderthals.

If we concretize the synergetic model of N. Moiseev, taking into account the material analyzed by us in the aspect of understanding the role of relationships between the sexes in anthroposociogenesis, we can describe in detail one of the parameters of the second bifurcation point associated with the transition from the purely biological evolution to the social (moral) one. The biological evolution has reached a dead end, caused by an unsolvable contradiction between the instinct of self-preservation and the instinct of reproduction. The only way out was to self-build a purely biological system with the superbiological fact of sexual abstinence during certain periods (taboo). They were the ones who violated the natural determinism, and if this did not happen, then an environmental catastrophe, mainly related to fights and sexual murders, would have been inevitable. Purely animal species could not deny themselves in the immediate satisfaction of their sexual needs; man rebelled against his own animal nature, its biological cause and effect, and began to arbitrarily dispose the determinants and prerogatives according to his plans. The replacement of natural social determinism by "totemic taboos, such as not allowing a son to have sexual relations with his own mother or sister, represented a global explosion" $[7]$. 


\subsection{The essence of the sexual contract}

Setting the sexual contract, man has created the conditions especially for environmental (survive as a species), and cultural adaptation in the form of an associative, pre-logical forms of thinking through which the gender relations can be seen as a mechanism for driving and guiding the development of anthropogenically system in crisis. All anthropogenic crises can be attributed to the evolutionary ones in the context of the synergetic concept of society and culture. Society is a non-equilibrium system, its mediating antientropic mechanism is culture (tools of production, language, mythology, morality, law, etc.). The latter (culture) must be changed according to the needs of the nonequilibrium system, because its mechanisms may lose its functionality. It can be concluded that all taboos in primitive society, including sexual ones, played the role of a mediating antientropic mechanism during the anthropogenic crisis. In accordance with male and female statuses and roles social reality is differentiated into the male and female societies. The societies with a dominant position of male social roles have features of patriarchy. The societies with a dominant position of female social roles are matriarchal. With the emergence of exogamy and gender a modern type of man is formed, and the primitive herd turns into a socially organized collective, including the socio-cultural factors, which begin to prevail in the relations between men and women, one of which is the system of gender and age normative characteristics (gender). In society "masculinity", "femininity" and" androgyny " are embodied in the system of gender characteristics. The concept of "gender" reflects the features of social interaction between men and women and we use it solely for the purpose of distinguishing between the biological and social in relations between men and women. Biological is denoted by the concepts of "sex", "sexual", "sexual relations"; currently, the concept of "sex" (sex) has become widely used. Sex is a combination of genes, genitals, hormones, and secondary sexual characteristics that divide people into two main categories: men, women, and, as an aberration, hermaphrodites. The sociocultural concept "gender" (from the English word gender) implies the psychological, social and cultural characteristics, according to the complex of which individuals relate themselves to one of the types: male, female or androgynous. The term "androgyny" in psychology is used to refer to the combination of male and female psychological traits in personality behavior. Note that the concept "gender" is closely related to "gender identity" - "selfawareness associated with cultural definitions of masculinity and femininity". It is possible to distinguish four components of the sexual definition of personality: biological gender, gender identity, gender ideals and sexual roles. In all gender theories the gender identity is determined by the assimilation of ideas about one's gender along with culture. The question is: do we feel fully male or female in accordance with our biological gender or do we experience discomfort due to one reason or another? Gender studies today unite the efforts of representatives of many social and humanitarian disciplines: sociologists, psychologists, cultural and literary historians, ethnographers and folklorists, etc. The most theories of gender focus on their practical significance, on the interest not so much in explaining the world as in changing it [8-21].

\subsection{The essence of matriarchy}

In general, the ethnographic data indicate an earlier origin of matrilineal law and a later origin of patrilineal law. The latter marked the start of patriarchy as a system of male social domination. But this does not mean that matriarchy is the opposite of patriarchy, i.e., as a system of female domination. Power, which was in the genus, was provided not by men, not by women, but by the collective. This was the power of the collective, the power of the family, realized in taboos, traditions and customs. In gender men and women were equal in 
their differences. Our research shows that the matriarchal system is an archaic form of social androgyny, i.e. a system in which the structure of a social organization is determined by a set of statuses and roles, based on the gender and age characteristics. Matriarchy is the era of formation of the feminine and masculine archetypes, being equally important for the development and functioning of the society. The settled life of the tribal society, required the preparation of food and supplies of fuel as well, thus, the importance of the land cultivation increased. Agriculture, originally hoe farming, is considered to be an invention of women. This fact created the conditions for the mystical identification of women with the earth, with fertility, with the source of life of the entire natural world. In this historical period motherhood takes on a sacred meaning, increasing of the birth rate was an urgent necessity. It provided the family with new hunters, working hands for the cultivation of the land. The very process of human birth was shrouded in mystery, the knowledge had not yet penetrated into its essence. Many tribes believed that children were resurrected by the totemic ancestors of the family, the birth of children, a sign of the sacred fertility of the earth, the children were inhabited by spirits who protected the family. There was the intuitive understanding of the idea that mankind preserved itself in the offspring.

It is noteworthy that women are identified with Nature and defined as the Mother Goddess. Among a number of peoples there has been the worship to mother goddesses, who simultaneously patronize agriculture until the beginning of the establishment of the class society: Isida in Egypt, Ishtar Manu on the banks of the Euphrates, Cybele in Asia Minor, Gaia among the Greeks and so on. However, it is a mistake to believe that the era of the tribal community demonstrated the power and dominance of the female principle at a certain point in history. At this time femininity is associated with natural elements, fertility, earth, motherhood, being the number of regulatory requirements that at first the girl then the woman was to follow: the girl was studied by her mother and the other women kind of different types of women's work, she had to undergo initiation, as adults, to respect a taboo, to obey the kind of marriage rules, to take care of children, keep focus. These norms acted as an expression of the will of the social collective. Their implementation provided a woman with a fairly honorable position in society. At the same time, the archetype of masculinity is formed, which obliges men to be bold, brave in hunting, merciless in the fight against strangers, to be able to endure physical pain, observe taboos, etc. Apparently, already within the borders of the primitive society there was an unsteadiness, mobility of male and female social characteristics (not their strict attachment to representatives of one or another sex), which is recorded in ethnographic observations. We can talk at this time about a certain level of complementarity of women's society with men's. The generic consanguineous community was an androgynous social organization, but its androgyny was not provided on an individual-personal level. This was the androgyny of the male and female group. The latter included children of both sexes up to a certain age. The third "bifurcation" in the history of the planet is associated with the acquisition of the skill of cultivation and cultivation of cereals, which was the result of the depletion of the ecological niche of hunting. At this time mammoths and large ungulates - the basis of the diet of Neolithic hunters - were destroyed. By switching to agriculture (already ploughed, male and not female occupation) and nomadic cattle breeding (exclusively male occupation), humanity not only emerged from another ecological crisis, but also created material conditions for the individual to break with the tribal community, which hinders the development of his individuality. The process of disintegration of the tribal community simultaneously meant the destruction of the primitive group androgyny, which determined the perception of it as "the great historical defeat of the female sex". In the future, the study of the genesis of relations between the sexes can be continued in the context of the models we have already developed. 


\section{Conclusion}

Our analysis allows us to draw the following conclusions. The data of anthropology, archeology, paleontology and ethnography presented in Russian and foreign literature indirectly show that the development of relations, interaction between the sexes in correlation (coontogenesis), along with the transition to systematic tool activity, production activity, played an extremely important role in the genesis of man and society (anthropogenesis and sociogenesis). The prehuman, i.e. actually animal herd, retreating from the zoological status system of "dominance", began to move towards the society. The supra-biological evolution eventually led to the formation of human communities: the genus (maternal generic community), the tribe, the state, etc., and gave the surrounding world the property of "human dimension". In parallel with the formation of the maternal ancestral community the process of becoming an archaic gender-and-age social structure (gender) went on. The gender structure was relatively harmonious, i.e. it was essentially a social androgyny (unity in difference and equality in cooperation between male and female social groups). The specifics of androgyny of the tribal community consisted in the fact that it was the result of the interaction of two groups, whose individuals, in accordance with their biological sex and age, fulfilled the requirements imposed on them by the collective, organized their lives in accordance with the certain norms. To comply with these standards the younger generation was prepared with the help of a special institute of initiations. On their side there was the collective as a whole and not its individuals and groups.

The evolution of gender relations in anthroposociogenesis is the basis for the transformation of purely biological energy into social energy. The main historical stages of this process are the successive forms of interaction between men and women within the primitive human collective, which are given in the following Table 1:

Table 1. The main historical stages of the gender relations in anthroposociogenesis (the successive forms of interaction between men and women within the primitive human collective).

\begin{tabular}{|l|l|}
\hline The stages & Description of the stage \\
\hline The first stage & $\begin{array}{l}\text { amorphous primitive human herd with } \\
\text { promiscuity, primitive human herd with } \\
\text { limited taboo promiscuity and the } \\
\text { appearance of sexual taboos, endogamy; }\end{array}$ \\
\hline The second stage & $\begin{array}{l}\text { the stage of displacement through taboo } \\
\text { of endogamy by exogamy, the } \\
\text { appearance of a dual-herd organization, } \\
\text { the marriage partner is already outside } \\
\text { of the consanguineous collective and the } \\
\text { structure of gender relations becomes } \\
\text { culturally determined, representing the } \\
\text { integrity of the male and female groups; }\end{array}$ \\
\hline The third stage & $\begin{array}{l}\text { change of the dual-herd organization to } \\
\text { the dual-generic one. }\end{array}$ \\
\hline
\end{tabular}

\section{References}

1. A. Kondakov, Teaching Queer Theory in Russia. QED: A Journal in GLBTQ Worldmaking, 3(2), 107-118 (2016) doi: 10.14321/qed.3.2.0107

2. M. Muravyeva, Gender and Crime in Russian History, Russian History, 43(3-4), 215220 (2016) doi: 10.1163/18763316-04304001 
3. J. Butler, A. Athanasiou, Dispossession: The Performative in the Political. Cambridge. Canadian Journal of Soiology/Cahiers Canadien de Soiologie, 39(1), 103-106 (2013) doi: $10.29173 /$ cjs 21561

4. P. Nordqvist, C. Smart, Relative strangers: family life, genes, and donor conception, (2014) doi: 10.1057/978

5. L. Shoberg, Gender and international security: feminist perspectives (2010) doi:10.4324/9780203866931

6. N. Yuval-Davies, Politics of belonging: intersectional competition (2011) doi:10.4135/9781446251041

7. E. Burman, Psychology, women and political practice in the UK (2011) doi: 10.1007/978-1-4419-9

8. L. Parisi, Transnational, In Our, Catherine Margaret; Braithwaite And Liechtenstein, Diane Marilyn (eds.). Rethinking women's and gender studies (2012) doi:10.4324/9780203134719

9. T. Lori, A. Hickey-Moody, Geophilosophy of masculinity: changing gender, aesthetics, and knowledge, Angels: journal of theoretical Humanities, 20(1), 1-10 (2015) doi: 10.1080/0969725x. 2015. 1017359

10. E. Weed, Gender and the lure of the post-Critical, A Journal of Feminist Cultural Studies, 27(2), 153-177 (2016) doi: 10.1215/10407391-3621757

11. A. Micah, Gender inequality in America (2018) doi: 10.13140 / RG.2.2.20188.44162

12. B. Judith, Parting ways: jewishness and the critique of zionism (2012) doi:10.1515/9780691184234-008

13. P. Bob, Masculinity in the making: from the local to the global (2016) doi: 10.1080/13552074.2016.1194037

14. D. Esther, C. Pantazis, Gender and poverty in Britain: Changes and continuities between 1999 and 2012, Journal of Poverty and Social Justice, 22(3) (2014) doi: 10.1332 / 175982714X14120853732082

15. B. Joseph, Theism, secularism, and sexual education in the United States, Sexuality Research and Social Policy: Journal of NSRC, 12(3), (2015) doi: 10.1007/s13178-015$0187-8$ 